\title{
Feeding behavior and capture success of turbot Psetta maxima larvae during the transition from upright to tilted swimming position
}

\author{
Eleonora Bruno ${ }^{1}$, Mohamed-Sofiane Mahjoub ${ }^{2}$, Benni Winding Hansen ${ }^{3}$, Peter Munk ${ }^{1}$ and \\ Josianne G. Støttrup ${ }^{1, *}$ \\ 1 Technical University of Denmark, National Institute of Aquatic Resources, Jægersborg Allé 1, 2920 Charlottenlund, Denmark \\ 2 DHI-NTU Research and Education Hub, 1 Cleantech Loop, 637141 Singapore \\ ${ }^{3}$ Roskilde University, Department of Science and Environment, 4000 Roskilde, Denmark
}

Received 4 March 2016 / Accepted 26 June 2017

Handling Editor: Pierre Boudry

\begin{abstract}
Aquaculture production of high-quality marine fish larvae might be hampered by poor success in larval initiation of exogenous feeding or the lack of appropriate live feed in their first feeding period. The period of larval metamorphosis may further constrain the successful rearing of flatfish larvae. In order to ascertain changes in feeding during metamorphosis of flatfish, we here compared feeding behavior when larvae of turbot Psetta maxima were either swimming upright or tilted. Using video recordings, we compared the attack rate and prey capture success between flexion (12-13 days-post-hatch, stage 4b-4c) swimming predominantly in upright position and post-flexion (16-17 days-post-hatch, stage 5a-5b) larvae in tilted swimming mode. Both larval groups were fed on copepod nauplii and copepodites. Our results showed a capture success of $<50 \%$ during the flexion stage, increasing to $73 \%$ in the post-flexion stage, and larvae were more successful when feeding on nauplii than when offered copepodite stages. An ontogenetic shift from intermittent to cruise swimming was observed during the metamorphosis concomitant with improved hunting skills. Thus larvae appeared to be able to successfully complete metamorphosis without compromising their feeding ability on copepod prey.
\end{abstract}

Keywords: Flatfish / Turbot / Larvae / Capture success / Feeding behavior / Copepods

\section{Introduction}

Aquaculture production of high-quality marine fish larvae could be impeded by problems such as an unsuccessful larval transition from endogenous to exogenous food (Shields, 2001), or an inability to provide suitable live feed (e.g. Rao, 2003). The process of metamorphosis might be an additional critical phase for larvae of flatfish species due to the profound morphological and physiological changes during this stage. After hatching, larvae of flatfishes have bilaterally symmetric bodies and swim in an upright position. During metamorphosis, one of the former lateral sides becomes the ventral side of the fish and they settle to the bottom. In particular, the migration of one of the eyes to the other side constitutes a dramatic change during development of flatfish larvae (Osse and Van den Boogaart, 1997). This transformation can affect the ability

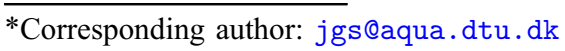

to search, locate and capture prey (Geffen et al., 2007). For example, it has been observed that feeding success of plaice Pleuronectes platessa could be reduced during eye migration, suggesting the need for a period of readjustment to the new position of eyes (Osse and Van den Boogaart, 1997; Blaxter, 1986). De La S. Sabate et al. (2008) reported an enhanced attack frequency for Japanese flounder Paralichthys olivaceus just before metamorphosis, while almost no attacks were observed at the peak of metamorphosis. On the other hand, the feeding behavior of spotted halibut Verasper variegatus began to increase just before metamorphosis and high attack frequencies were maintained until the juvenile stage of this species. For larvae of turbot Psetta maxima Person-Le-Ruyet (2010) observed "visible swimming disturbances" during the transition from a pelagic to a benthic status.

In this study, we present an analysis of turbot larval behavior to assess whether the transition period from the 
upright (flexion stage) to the tilted form (post-flexion) could be a critical feeding phase. Turbot is a highly valued species in aquaculture (Person-Le-Ruyet, 2010) and the most farmed flatfish species in Europe (Rodríguez Villanueva and Fernandez Souto, 2017). Because of recent declines in natural habitats, reared turbot is also important for stock enhancement of natural populations, e.g. in Denmark and Spain (Iglesias et al., 2003; Sparrevohn and Støttrup, 2007). As for other cultured flatfish species, turbot production experiences high losses of fry due to low survival rates (Rodríguez Villanueva and Fernandez Souto, 2017). Turbot larvae are commonly reared using live prey as feed, and these need to be nutritionally enriched to meet the nutritional requirements of the larvae as they are often not part of the natural diet of marine fish larvae. Rotifers $(\sim 250 \mu \mathrm{m})$, mainly of the species Brachionus plicatilis, are widely used as a first feed, and these are subsequently replaced by larger prey, such as the nauplii of the brine shrimp Artemia $(500 \mu \mathrm{m})$ (Conceição et al., 2010). However, flatfish larvae that are fed rotifers and Artemia often develop malpigmentation. In an investigation of turbot larvae pigmentation Hamre et al. (2007) showed that $>90 \%$ of Atlantic halibut larvae fed Artemia were malpigmented, whereas only $32 \%$ of the larvae fed copepods were malpigmented.

In Denmark, turbot larvae are reared on calanoid copepods in semi-intensive land-based systems utilizing a phytoplankton-zooplankton food web (Engell-Sørensen et al., 2004; Blanda et al., 2016). Calanoid copepods, the natural prey of marine fish larvae, are superior in nutritional value compared to rotifers and Artemia (Evjemo et al., 2003; van der Meeren et al., 2008; Øie et al., 2017). Larval feeding is also influenced by the behavior of copepods (Støttrup and Norsker, 1997; Bruno et al., 2017). Compared to rotifers, higher feeding rates are seen in the presence of copepods, probably because their swimming behavior relative to that of rotifers triggers a better feeding response (Buskey et al., 1993; Wilcox et al., 2006). Furthermore, the larvae would be offered a broader range of prey sizes when feeding them on different stages of copepods as compared to feeding on rotifers and Artemia only. In spite of the high nutritional value of offered copepods, the semiintensive rearing systems are still affected by relatively low larval survival (<20\% production cycle ${ }^{-1}$ ) (Blanda et al., 2016; Jepsen et al., 2017). To improve the rearing of larvae in semi-intensive systems, there is a need to gain further information on the predator-prey interactions. Thus, in order to avail further insight into feeding behavior and success during the metamorphosing period of turbot we compared swimming and feeding of larvae divided in two groups according to their length and developmental stage: in the flexion stage when the larvae have a bilateral body and their swimming is upright and in the post-flexion stage, when about half of the right eye can be seen from the left side of the turbot larva.

\section{Materials and methods}

\subsection{Production system}

The investigation took place in 2012 in a land based fish farm (Maximus A/S) located at Limfjorden, Denmark. The farm uses an outdoor semi-intensive production system where turbot larvae are fed live feed from the yolk stage until end of metamorphosis. Turbot larvae were sampled from outdoor
Table 1. Days-post-hatch (DPH), number of turbot larvae studied for each recording, larval standard length (flexion $n=23$; post-flexion $n=16$ ), larval developmental stages (after Al-Maghazachi and Gibson, 1984).

\begin{tabular}{lccl}
\hline DPH & Number larvae & $\begin{array}{l}\text { Standard length } \\
(\mathrm{mm} \pm \mathrm{SE})\end{array}$ & Developmental stage \\
\hline $12-13$ & $3 \pm 1$ & $8.0 \pm 0.2$ & Flexion (stage 4c-4d) \\
$16-17$ & $5 \pm 0$ & $11.5 \pm 1.2$ & Post-flexion (stage 5a-5b) \\
\hline
\end{tabular}

open-top concrete tanks: 2 large tanks (volume: $220 \mathrm{~m}^{3}$, depth: $2.5 \mathrm{~m}$ ) and 1 smaller tank (volume: $54 \mathrm{~m}^{3}$, depth: $1.5 \mathrm{~m}$ ). All tanks were filled with pre-filtered water from the estuary (Hydrotech HDF 2007-2H drum filter, Sweden, fitted with $50 \mu \mathrm{m}$ screens). No water renewal or mechanical mixing was applied and no organic nutrients were added to the tanks.

Copepods were provided prior to the addition of turbot larvae, allowing the development of a planktonic prey community for the turbot larvae. Copepodites and adult copepods were collected by a wheel filter (UNIK Rotating Wheel Filter Type 1200, Oslo, Norway, mesh size $250 \mu \mathrm{m}$ ) which filtered the seawater pumped to the concrete tanks from a storage tank where a seeding culture of copepods is maintained to prevent parasites in the culture system (an extensive description of the copepod collection method with UNIK filters is made by van der Meeren et al., 2014). Generally a species succession is seen during the annual production period: Acartia spp. dominates in spring and early summer, whereas Centropages hamatus dominates in late summer (Jepsen et al., 2017). The monitoring of abiotic factors and of the planktonic community in the tanks is described in detail in Blanda et al. (2016).

A batch of yolk-sac turbot larvae ( $<48 \mathrm{~h}$ after hatching) was obtained from Stolt Sea Farm AS (Norway). The larvae were gently oxygenated to keep them in suspension and water from the tanks was slowly added to their transport box to acclimatize them during $\sim 12 \mathrm{~h}$. Then, the larvae were counted and released into the tanks. The density was $0.05-0.06$ yolk sac larvae $\mathrm{L}^{-1}$ (12 819 larvae per tank in the $220 \mathrm{~m}^{3}$ tanks and 2700 in the $54 \mathrm{~m}^{3}$ tank).

\subsection{Experimental procedure}

Larvae 12-17 day-post-hatch (DPH) were gently sampled from the tanks with a hand-held plankton net. The number of sampled fish larvae varied due to difficulties in capturing them on the given sampling day. We studied and measured in total 13 larvae in the flexion stage (DPH 12-13), and 15 larvae in the postflexion (DPH 16-17) stage (Table 1). The developmental stages, as described by Al-Maghazachi and Gibson (1984), and pictures of these two stages with their descriptions are provided in Figure 1. Copepod prey (Acartia spp. and Centropages hamatus) was provided at a density of $500 \mathrm{~L}^{-1}$ and consisted of a mixture of mainly nauplii $(50 \%$, within the size range $50-250 \mu \mathrm{m})$, and copepodites and adults $(50 \%,>250 \mu \mathrm{m})$.

For the experiments we used a glass aquarium $(15 \mathrm{~h} \times 16$ $\mathrm{w} \times 7 \mathrm{~d}, \mathrm{~cm})$ filled with $45 \mu \mathrm{m}$ filtered seawater from the production tanks (salinity 29\%o). The turbot larvae were randomly captured from the tanks and transferred into a $4 \mathrm{~L}$ 


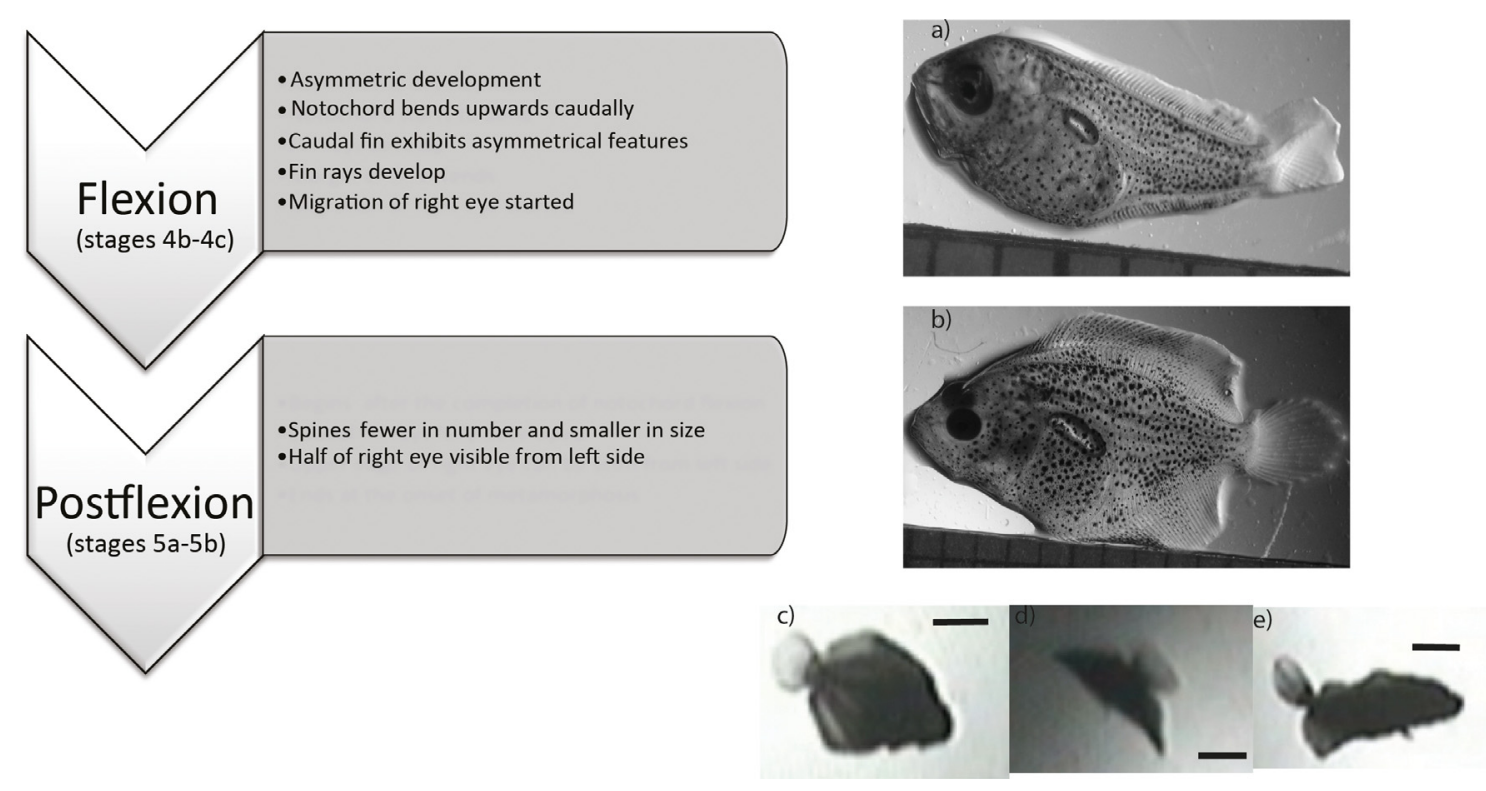

Fig. 1. Examples of turbot larvae in the development stage: (a) flexion, (b) post-flexion with the description of each stage and pictures of postflexion turbot larvae in upright (c) and different degrees of tilted positions: (d) $38^{\circ}$, (e) $\sim 90^{\circ}$. Scale bars $0.25 \mathrm{~cm}$ for (c)-(e).

Table 2. Definition of turbot larval categories, or Modal Action Patterns (MAPs, after Brown, 1986).

\begin{tabular}{ll}
\hline \multicolumn{1}{c}{ Definition of categories (Larval Modal Action Patterns (MAPs)) } \\
\hline $\begin{array}{l}\text { Swim } \\
\text { Pause }\end{array}$ & $\begin{array}{l}\text { The larva swims actively } \\
\text { The larva is motionless for } \leq 2 \mathrm{~s} \text { (similar } \\
\text { to non-swimming in Munk, 1995) including when the } \\
\text { larva rests immobile on the bottom of the aquarium }\end{array}$ \\
S-shape & $\begin{array}{l}\text { The larva make an S-shape with its body } \\
\text { when locating a prey }\end{array}$ \\
Tilted & $\begin{array}{l}\text { The tilted larva (benthic) makes an S-shape } \\
\text { Sith its body when locating a prey }\end{array}$ \\
Attack & $\begin{array}{l}\text { The larva performs a short forward burst } \\
\text { while opening its mouth (after Munk, 1995) }\end{array}$ \\
Shake & $\begin{array}{l}\text { Several rapid sideways movements propagating } \\
\text { from head to tail }\end{array}$ \\
&
\end{tabular}

bucket $3 \mathrm{~h}$ before each recording. The sampled larvae were not fed during these $3 \mathrm{~h}$ and water was gently air-bubbled during the period. The larvae (3-5 at each experiment; Table 1) were then gently transferred into the experimental aquarium where they were allowed to acclimatize for a period of $30 \mathrm{~min}$ before starting the recording. The focus area of the video prior to each recording was calibrated using a ruler vertically positioned in the middle of the aquarium. The copepods were added to the experimental aquarium, where after the recording was started. For each replicate experiment, new larvae were used.

The experiments took place in a dark room, to improve visual contrast and thus facilitate the analysis of the videos. The video camera used was a Sony DXC-101P CCD (Japan) with mounted lens (Tamron EOS c80-210 mm, the range used was 100$120 \mathrm{~mm})$. The camera was connected to a video converter (Grabster AU 350), to provide a close-up view of the aquarium. The frame rate was 25 frames s${ }^{-1}$. The camera was set on an optic bench in front of the aquarium, and a collimator lens was positioned between the aquarium and the used IR diode $(880 \mathrm{~nm})$, to provide infrared light to the camera. The distance between the diode and the aquarium was $37 \mathrm{~cm}$. A portable programmable power supply (Iso-tech IPS 2010 3 V) was connected to the IR diode. One desktop lamp (halogen bulb $40 \mathrm{~W}$ ) was positioned above the aquarium at a distance of $25 \mathrm{~cm}$, to provide light to the larvae. Light intensity was measured at the beginning of each recording with a light-meter (Li-COR Model LI-185B, USA) and was throughout ca. $170 \mu \mathrm{mol} \mathrm{m}^{-2} \mathrm{~s}^{-1}$. The distance between the aquarium and the camera lens was $162 \mathrm{~cm}$. The recorded area was $6.7 \pm 1.3 \mathrm{~cm}$ wide and $5.5 \pm 1.1 \mathrm{~cm}$ high. Only larvae in focus were analyzed.

Water temperature was checked at the beginning and at the end of each recording $\left(18 \pm 0.5^{\circ} \mathrm{C}\right.$ and $19 \pm 0.5^{\circ} \mathrm{C}$, respectively). At the end of each recording session which lasted $60 \mathrm{~min}$, the larvae were sedated by gently immerging them in filtered seawater with addition of carbonated water, and pictures were taken with a digital camera (Nikon Coolpix L100, Japan) mounted on a dissection microscope (Olympus SZ40, USA). The standard length of the larvae was measured using the image analysis software ImageJ (https://imagej.nih.gov/ij/). Developmental stages (1-5) were determined using the scale developed by Al-Maghazachi and Gibson (1984).

\subsection{Behavioral analysis}

The video recordings were analyzed according to larval foraging categories (Modal Action Patterns), abbreviated as MAPs (Brown, 1986) (Table 2). A kinematic diagram was compiled of transition rates from one behavioral category to another, describing the probability of a change from one MAP to another. Every single larva was visually tracked from when they entered the field of view of the camera to their disappearance from this view. The first minutes of each recording after the addition of the copepods were excluded from the final analysis due to the temporary high water turbulence. 
The attack events were identified as larval burst forward toward a prey. The attack success was assessed from a shake of the head by the larvae and/or disappearance of the attacked copepod.

\subsection{Statistical analysis}

We tested whether the time allocated to the MAPs "Swim", "Pause", "S-shape", "Tilted S-shape", "Attack" and "Shake" was statistically different between flexion and post-flexion stages. As the individual observations within a track could not be assumed as being independent, we used a non-parametric bootstrap test. For the observed data the standard chi-square statistics (T-obs) was computed for the hypothesis $H_{0}$ : the distribution of time on the six considered MAPs is the same for all days. Then $N=1000$ datasets were bootstrapped by randomly assigning days to the observed tracks. If the $H_{0}$ was valid those should be equally likely datasets. The chisquare test statistics was then computed for the bootstrapped datasets giving $N$ samples of the distribution of the test statistics $T$. The $p$ value for $H_{0}$ is now the fraction of the $T$ simulated, which are greater than $T$-obs.

To test whether the developmental stage had an effect on rates of performed S-shapes, Attacks and targeted prey, $t$-tests and $z$-tests were run in SigmaPlot (Version 12.5, 2015). Results were considered significant if $p<0.05$.

Tests for time spent in individual MAP-categories were set up in the same way, and the Bonferroni correction for multiple testing was applied to counteract the problem that some tests could have been statistically significant by chance. Behavioral transition matrices were constructed for each stage by tabulating the frequencies of changes from one behavioral MAP to another MAP. We also performed a bootstrap analysis to test whether there was a significant difference in behavioral transitions between flexion and post-flexion stages. The criterion for significance was set at $p<0.05$. These tests were run in R Ver. 3.0.3 (R Development Core Team, 2014).

\section{Results}

\subsection{Larval swimming}

In the flexion phase (Fig. 1a) turbot larvae exhibited a swimming movement during which both caudal and pectoral fins were continuously moving. This swimming mode has been defined as "caudal-fin" swimming, as the movements of the caudal part of the body are pronounced (Kohno, 2001). The active swimming was interrupted by short breaks, Pause (defined MAP's are hereafter in italics), in which neither the caudal nor the pectoral fins were moving. During the flexion stage Pause was the predominant category (45\%) (Bootstrap test; $p<0.001$ ) (Fig. 2).

In the post-flexion stage (Fig. 1b), swimming involved also use of dorsal and anal fins and the larvae switched between the pelagic, upright swimming (Fig. 1c), and tilted swimming, with a variable degree of tilting $\left(56^{\circ} \pm 7^{\circ}, n=6\right)$ (Fig. 1d, e). The Swim category was predominant $(69 \%)$, while the Pause category was only performed $1 \%$ of the time (Bootstrap test; $p<0.001$ ) (Fig. 2). The overall bootstrap test showed a significant difference in the distribution of behavioral patterns (MAPs) between flexion and post-flexion stages (Fig. 2)

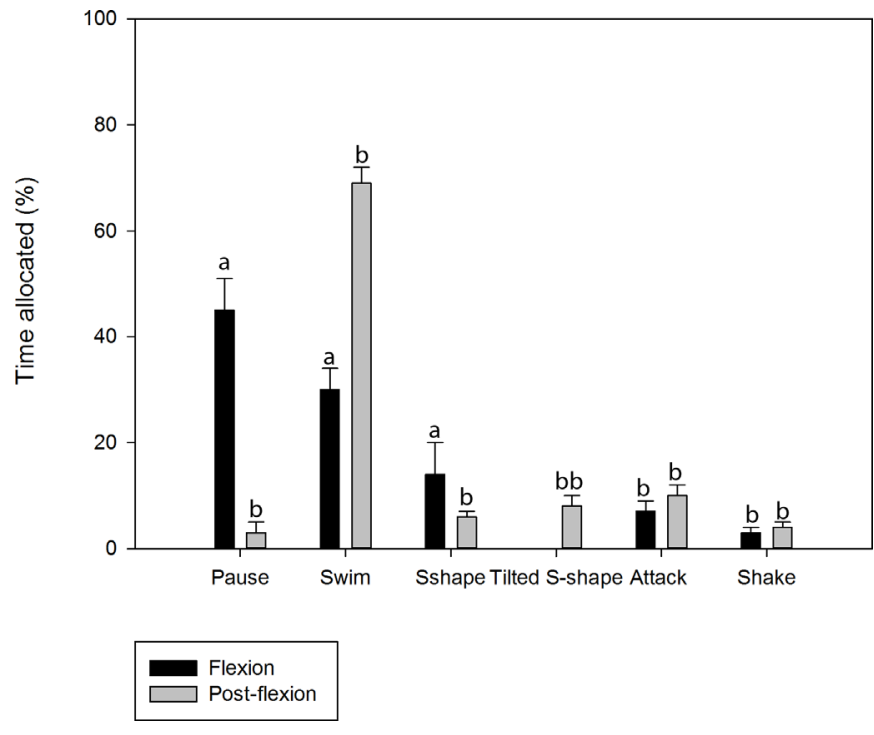

Fig. 2. Percent of time allocated to the MAPs Pause, Swim, S-shape, Tilted S-shape, Attack, Shake. Bars that share the same letter are not significantly different $(p<0.05)$ within each MAP category. Error bars indicate $95 \%$ confidence intervals.

$(p<0.0001)$. The behavioral transition from Swim to Pause action in the flexion stage was significantly higher $(20 \%)$ than during the post-flexion stage $(<1 \%)$ (Bootstrap test; $p<0.001)$ (Fig. 3).

\subsection{Attacks}

Turbot larvae in attack posture bend their body in an S-shape posture from which they suddenly straighten and dart forward, as described by Jones (1972). However, not all larvae perform an $S$-shape during their preparation of an attack. The transition rate from Swim to Attack, without performing an S-shape to prepare the attack, was not significantly different between the flexion and the post-flexion stages (Fig. 3).

The rate of $S$-shapes decreased significantly from the flexion to the post-flexion stage, from $2.5 \pm 0.8$ to $1.9 \pm 0.6 \mathrm{~S}$ shapes $\min ^{-1}$ ( $t$-test; $p<0.05$ ) (Fig. 4). The duration of the $\mathrm{S}$-shape was not significantly different from the flexion to the post-flexion stage.

The larvae performed more than one $S$-shape (an S-shape followed by another $S$-shape after a $1-2$ s pause) $36 \%$ of the times during flexion stage against $<1 \%$ of the times during the post-flexion stage (Bootstrap test; $p<0.0001$ ). The performance of an $S$-shape did not always lead to an Attack. The rate of interrupted attacks, i.e. S-shape followed by a Swim action instead of an Attack, was not significantly different from the flexion to the post-flexion stage (Bootstrap test; $p>0.05$ ).

The transition rate from $S$-shape to Attack increased from the flexion to the post-flexion stage, from $41 \%$ to $71 \%$ (Bootstrap test; $p<0.001$ ) (Fig. 3). The total attack rate increased from the flexion to the post-flexion stage, from $3.3 \pm 0.1$ to $4.5 \pm 0.5$ attacks $\min ^{-1}$ ( $t$-test; $p<0.001$ ) (Fig. 4 ). In the flexion stage, attacks were successful in $41 \%$ of the cases, while the successful attacks reached $73 \%$ in the postflexion stage $(t$-test; $p<0.001)$. After a successful capture, turbot larvae made a Shake action. 


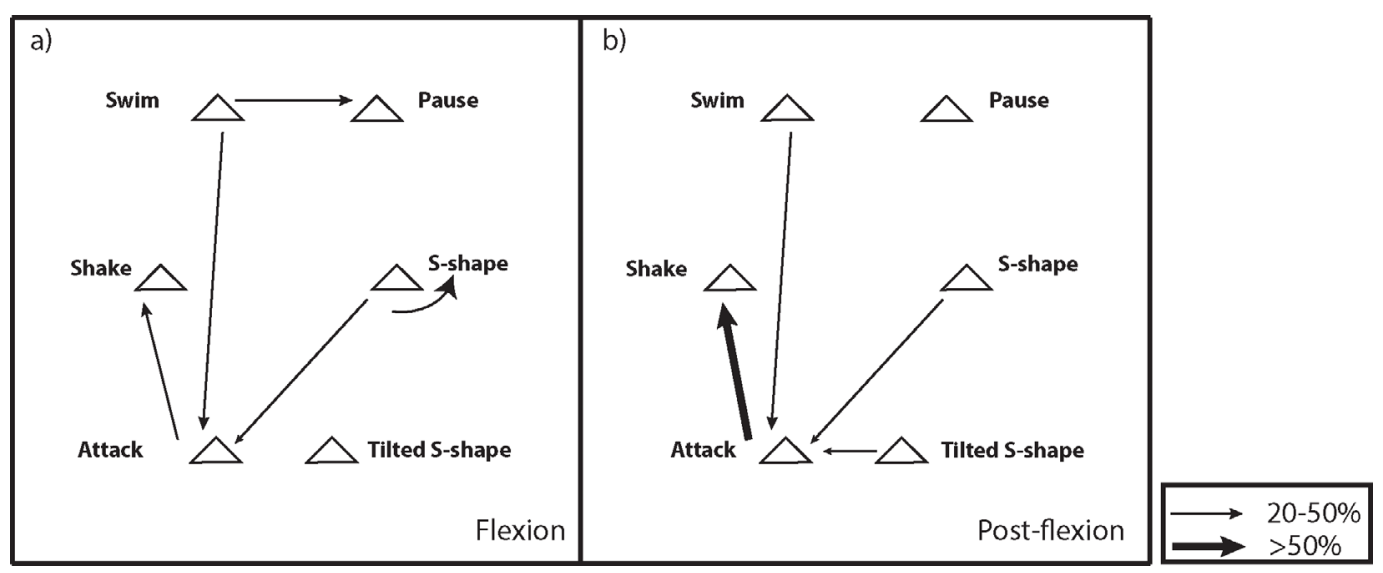

Fig. 3. Synthetic kinematic diagrams illustrating the most frequent feeding behavioral transitions during (a) flexion and (b) post-flexion. The light arrows indicate a behavioral transition of $20-50 \%$, the bold arrows indicate a behavioral transition of $>50 \%$.

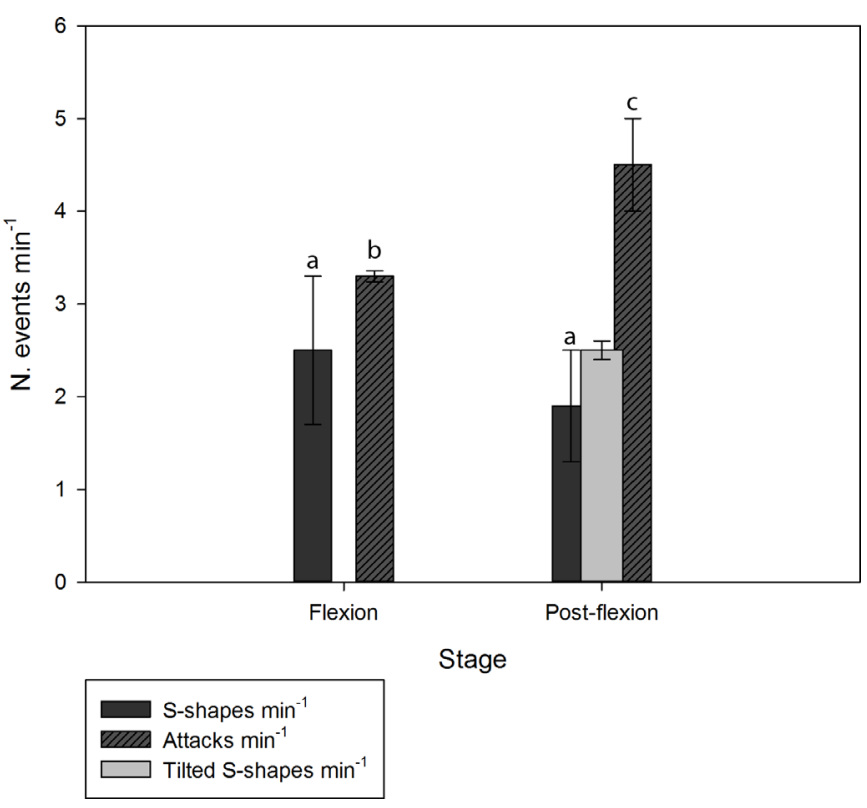

Fig. 4. S-shapes and attack rates of turbot larvae in the flexion and post-flexion stage. Values are given as mean $\pm \mathrm{SE}$.

In the post-flexion stage, turbot larvae also performed another kind of preparation to the Attack other than the welldescribed S-shape. It was a Tilted S-shape, where the body was tilted, bent and stabilized by the movement of the dorsal and anal fins. In this stage, turbot larvae performed $2.5 \pm 0.1$ Tilted $S$-shapes $\min ^{-1}$ (Fig. 4). The Attack was performed either with an upright or tilted posture. The rate of successful upright Attacks of total upright Attacks was slightly lower than the rate of successful tilted attacks on total tilted Attacks, but not statistically different $(z$-test; $p=0.059)$.

The prey type (nauplii or copepodites) was determined in more than $50 \%$ of the Attacks in the post-flexion stage. Nauplii were targeted in $100 \%$ of the attacks during the flexion stage, and in $67 \%$ of the Attacks during the post-flexion stage, the difference being significantly different ( $z$-test; $p<0.001$ ). Rate of total Attacks was higher on nauplii than on copepodites (Fig. 5), and also the rate of successful Attacks was higher on nauplii (63\%) than on copepodites $(15 \%)(z$-test; $p<0.001)$ (Fig. 5).

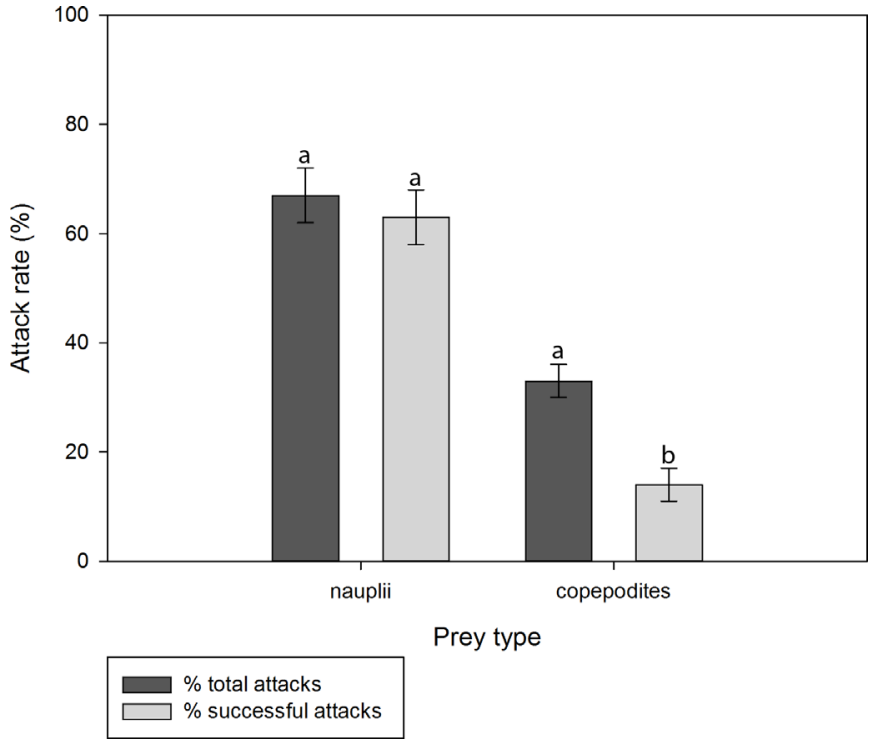

Fig. 5. Post-flexion attacks in relation to prey type: (a) rate of total attacks and (b) rate of successful attacks on nauplii and copepodites. Bars that share the same letter are not significantly different $(p<0.05)$ within each prey type. Values are given as mean \pm SE.

\section{Discussion}

The transition period from the pelagic to the benthic stage in flatfish larvae, occurring during metamorphosis, is characterized by profound morphological and physiological changes. In the present study, we assessed the behavioral traits related to feeding of turbot larvae during the transition from an upright to a tilted position that could indicate feeding constraints and thus affect the success of turbot larval rearing in aquaculture.

The level of Swim in the flexion stage was significantly lower than in the post-flexion stage. A higher level of activity during the post-flexion phase has been previously observed in turbot larvae (Skiftesvik, 1992). We also observed that turbot larvae shifted from a "saltatory" strategy in the flexion stage, pausing for brief periods, toward a "cruise" predatory behavior in the post-flexion stage, showing a more continuous 
swimming. The same was observed in the larvae of the flatfish witch flounder Glyptocephalus cynoglossus (Rabe and Brown, 2001). Intermittent motion is characteristic for early turbot larvae (Cunha et al., 2007) and often first-feeding larvae interrupt their swimming by "routine" turns (own observations). An important difference between "saltatory" and "cruise" strategies is that during the first, the search for prey items only occurs during the pauses in larval swimming (O'Brien et al., 1990; Hunt von Herbing and Gallager, 2000). The shift from a "saltatory" to a "cruise" predatory behavior indicates that an ontogenetic shift in swimming mode has taken place.

The aiming behavior (use of S-shape, Tilted S-shape) changed from flexion to post-flexion. In both stages turbot larvae performed an $S$-shape to prepare the attack. Our results show, however, a decline in the frequency of $S$-shapes from the flexion to the post-flexion stage. A decline in the frequency of $S$-shapes has been observed in other studies, for example, for larvae of Japanese flounder P. olivaceus (Dou et al., 2000) and of European sea bass Dicentrarchus labrax (Georgalas et al., 2007). However, during the post-flexion stage, turbot larvae also performed Tilted S-shapes. The decrease in S-shapes and the introduction of Tilted S-shapes during the post-flexion stage show that turbot larvae still would have to aim at the prey when in tilted position, but need to reposition. Interestingly, we observed that the performance of multiple $S$-shapes declined significantly from the flexion to the post-flexion stage, performance of multiple S-shapes indicate failure to aim correctly, and hence it appears that the larvae during this transition improved their predator skills. S-shapes did not always lead to an attack, and such interrupted Attacks are usually defined "aborted" Attacks, and such have been reported for other species, for example larval cod Gadus morhua (Hunt von Herbing and Gallager, 2000). The aborted Attacks could be related to the challenges in prey capturing due to the prey moving prior to the Attack.

We observed that Attack success increased from the flexion to the post-flexion stage. This improvement would be related to the morphological and physiological development during ontogeny. For example, rods appear in the retina at stage 5, and the presence of this type of photoreceptors increases the visual capabilities by improving vision in low light conditions (de Miguel Villegas et al., 1997). Further, the gut develops (Segner et al., 1994) and the feeding structures become more complex during ontogeny (Hunt von Herbing and Gallager, 2000). The increasing attack success during larval ontogeny have been observed in other species, like larval cod (Hunt von Herbing and Gallager, 2000) and Atlantic herring Clupea harengus larvae (Utne-Palm, 2004).

The significant increase in both attack rate and in capture success from the flexion to the post-flexion stage show, that this transition does not hamper feeding of turbot larvae at this stage. During post-flexion, about half of the right eye can be seen from the left side, but turbot larvae might still rely on a binocular fixation on the prey, as when larvae were in their symmetrical stage (Osse and Van den Boogaart, 1997). A study on Southern flounder Paralichthys lethostigma showed that tilted behavior can be occur independently of the asymmetric position of the eye (Schreiber, 2006). Thus, the transition from flexion to post-flexion stage might be a learning phase, aiming at prey from a tilted position. Estimates of attack rates during metamorphosis differ between experiments on flatfish species. De La S. Sabate et al. (2008) observed that in Japanese flounder the attack frequency was highest just before metamorphosis, while almost no attacks were observed in the middle of the metamorphosis period. De La S. Sabate et al. (2008) also investigated spotted halibut, for which the feeding behavior began to increase just before metamorphosis and a high attack frequency was maintained until the juvenile stage.

A relatively low capture success $(<50 \%)$ in the flexion stage points to difficulties in catching the prey, here copepods. The type of swimming behavior of the different copepod species could represent a challenge for turbot larvae. In the present study, we did not distinguish between Acartia spp. or Centropages hamatus during the video analysis, however, we noticed that larvae captured more nauplii than copepodites. Studies on the effect of specific prey species and developmental stages could complement the present results. In the flexion stage of turbot larvae the prey sizes in the range we offered the larvae does not constitute a limitation to ingestion. The development of the jaws and sucking system of turbot is being completed at flexion stage, e.g. around DPH 13 turbot larvae develop tooth-bearing pharyngeal jaws and a toothless buccal jaw (Wagemans et al., 1998). These morphological features, and the obtained mouth size, help the larvae to capture relatively large prey $(500-1000 \mu \mathrm{m}$, like Artemia nauplii and metanauplii) (Wagemans et al., 1998). The upper jaws could extend to create a pre-buccal cavity, and this capability might be influenced by the asymmetries at metamorphosis (Wagemans et al., 1998). At the age of our oldest larvae, 16-17 DPH, all of the sospensorium and hyoid arch elements start to ossify, suggesting that at this stage the larvae can generate stronger negative pressure for sucking, defined as the "sucking + biting" stage (Kohno, 2001).

In conclusion our results suggest that transition from an upright to a tilted larva is rather a phase of development than a critical phase to larval feeding and survival, in contrast to what was observed in other flatfish species (e.g. Japanese flounder and spotted halibut). During this transition phase, the larvae proved to be more efficient in capturing their prey. There is an ontogenetic shift from intermittent to cruise swimming, and the hunting skills of turbot larvae are apparently improved. The feeding processes are inevitably dependent on the type of prey offered and we encourage complementary studies to investigate the effect of specific copepod species and developmental stages on the feeding during this interesting ontogenetic phase in the early life of flatfish.

Acknowledgments. We are grateful to Anders Thinggaard Pedersen, Site Manager at Maximus A/S for having provided the experimental facilities for the present study, for all his support and good suggestions. Dr. Hans Henrik Jakobsen provided indispensable equipment, and improved the work with good suggestions. Thomas Allan Rayner supported our work with ideas and suggestions. We are also grateful to statistician Anders Nielsen for his precious help with the statistical analysis of the occurrence probability of larval MAPs. The study was supported by the Danish National Strategic Research Council IMPAQ grant no. 10-093522 awarded to Benni W. Hansen. 


\section{References}

Al-Maghazachi SJ, Gibson R. 1984. The developmental stages of larval turbot, Scophthalmus maximus (L.). J Exp Mar Biol Ecol 82: $35-51$.

Blanda E, Hansen BW, Højgaard JK, Jepsen PM, Pedersen MF, Rayner TA, Thoisen CV, Jakobsen HH. 2016. Inorganic nitrogen addition in a semi-intensive turbot larval aquaculture system: effects on phytoplankton and zooplankton composition. Aquac Res 47: 3913-3933.

Blaxter JHS. 1986. Development of sense organs and behaviour in teleost larvae with special reference to feeding and predation avoidance. Trans Am Fish Soc 115: 98-114.

Brown JA. 1986. The development of feeding behaviour in the lumpfish, Cyclopterus lumpus. J Fish Biol 29: 171-178.

Bruno E, Højgaard JK, Hansen BW, Munk P, Støttrup JG. 2017. Influence of swimming behaviour of copepod nauplii on the foraging of larval turbot (Scophthalmus maximus). Aquacult Int, submitted.

Buskey EJ, Coulter C, Strom S. 1993. Locomotory patterns of microzooplankton: potential effects on food selectivity of larval fish. Bull Mar Sci 53: 29-43.

Conceição LEC, Yúfera M, Makridis P, Morais S, Dinis MT. 2010. Live feeds for early stages of fish rearing. Aquac Res 41: 613-640.

Cunha I, Conceição LEC, Planas M. 2007. Energy allocation and metabolic scope in early turbot, Scophthalmus maximus, larvae. Mar Biol 151: 1397-1405.

de Miguel Villegas E, Dans MJD, Paz-Andrade Castillo C, Alvarez RA. 1997. Development of the eye in the turbot Psetta maxima (Teleosti) from hatching through metamorphosis. J Morphol 233: 31-42.

Dou S, Seikai T, Tsukamoto K. 2000. Feeding behaviour of Japanese flounder larvae under laboratory conditions. J Fish Biol 56: 654-666.

Engell-Sørensen K, Støttrup JG, Holmstrup M. 2004. Rearing of flounder (Platichthys flesus) juveniles in semiextensive systems. Aquaculture 230: 475-491.

Evjemo JO, Reitan KI, Olsen Y. 2003. Copepods as live food organisms in the larval rearing of halibut larvae (Hippoglossus hippoglossus L.) with special emphasis on the nutritional value. Aquaculture 227: 191-210.

Geffen AJ, van der Veer HW, Nash RDM. 2007. The cost of metamorphosis in flatfishes. J Sea Res 58: 35-45.

Georgalas V, Malavasi S, Franzoi P, Torricelli P. 2007. Swimming activity and feeding behaviour of larval European sea bass (Dicentrarchus labrax L.): effects of ontogeny and increasing food density. Aquaculture 264: 418-427.

Hamre K, Holen E, Moren M. 2007. Pigmentation and eye migration in Atlantic halibut (Hippoglossus hippoglossus L.) larvae: new findings and hypotheses. Aquac Nutr 13: 65-80.

Hunt von Herbing I, Gallager SM. 2000. Foraging behavior in early Atlantic cod larvae (Gadus morhua) feeding on a protozoan (Balanion sp.) and a copepod nauplius (Pseudodiaptomus sp.). Mar Biol 136: 591-602.

Iglesias J, Ojea G, Otero JJ, Fuentes L, Ellis T. 2003. Comparison of mortality of wild and released reared 0-group turbot, Scophthalmus maximus, on an exposed beach (Ria de Vigo, NW Spain) and a study of the population dynamics and ecology of the natural population. Fish Manag Ecol 10: 51-59.

Jepsen PM, Jakobsen HH, Rayner TA, Blanda E, Novac A, EngellSørensen K, Hansen BW. 2017. A production season of turbot larvae Scophthalmus maximus(Linnaeus 1758) reared on cope- pods in a Danish semi-intensive outdoor system. Aquac Res 48: 4958-4974.

Jones A. 1972. Studies on egg development and larval rearing of turbot, Scophthalmus maximus L., and brill, Scophthalmus rhombus L., in the laboratory. J Mar Biol Assoc UK 52: 965-986.

Kohno H. 2001. Development of swimming and feeding functions in larval turbot, Psetta maxima, reared in the laboratory. Turk J Fish Aquat Sci 1: 7-15.

O'Brien WJ, Browman HI, Evans BI. 1990. Search strategies of foraging animals. Am Sci 78: 152-160.

Munk P. 1995. Foraging behaviour of larval cod (Gadus morhua) influenced by prey density and hunger. Mar Biol 122: 205-212.

Øie G, Galloway T, Sørøy M, Holmvaag Hansen M, Norheim IA, Halseth CK, Almli M, Berg M, Gagnat MR, Wold PA, Attramadal K, Hagemann A, Evjemo JO, Kjørsvik E. 2017. Effect of cultivated copepods (Acartia tonsa) in first-feeding of Atlantic cod (Gadus morhua) and Ballan wrasse (Labrus bergylta) larvae. Aquac Nutr 23: 3-17.

Osse JWM, Van den Boogaart JGM. 1997. Size of flatfish larvae at transformation, functional demands and historical constraints. J Sea Res 37: 229-239.

Person-Le-Ruyet J. 2010. Turbot culture. In: Daniels HV, Watanabe WO, eds. Practical Flatfish Culture and Stock enhancement. Oxford: Wiley-Blackwell, pp. 125-139.

R Development Core Team. 2014. R: a language and environment for statistical computing. Vienna: R Foundation for Statistical Computing. Available from: http://www.R-project.org.

Rabe J, Brown JA. 2001. The behavior, growth, and survival of witch flounder (Glyptocephalus cynoglossus) larvae in relation to prey availability: adaptations to an extended larval period. Fish Bull 99: 465-474.

Rao TR. 2003. Ecological and ethological perspectives in larval fish feeding. J Appl Aquac 13: 145-178.

Rodríguez Villanueva JL, Fernandez Souto B. 2017. Cultured Aquatic Species Information Programme - Psetta maxima (Linnaeus 1758).

De La S. Sabate F, Sakakura Y, Hagiwara A. 2008. Comparison of behavioural development between Japanese flounder (Paralichthys olivaceus) and spotted halibut (Verasper variegatus) during early life stages. J Appl Ichthyol 24: 248-255.

Schreiber AM. 2006. Asymmetric craniofacial remodeling and lateralized behavior in larval flatfish. J Exp Biol 209: 610-621.

Segner H, Storch V, Reinecke M, Kloas W, Hanke W. 1994. The development of functional digestive and metabolic organs in turbot, Scophthalmus maximus. Mar Biol 119: 471-486.

Shields R. 2001. Larviculture of marine finfish in Europe. Aquaculture 200: 55-88.

Skiftesvik AB. 1992. Changes in behaviour at onset of exogenous feeding in marine fish larvae. Can J Fish Aquat Sci 49: 1570-1572.

Sparrevohn CR, Støttrup JG. 2007. Post-release survival and feeding in reared turbot. J Sea Res 57: 151-161.

Støttrup JG, Norsker NH. 1997. Production and use of copepods in marine fish larviculture. Aquaculture 155: 231-247.

Utne-Palm AC. 2004. Effects of larvae ontogeny, turbidity, and turbulence on prey attack rate and swimming activity of Atlantic herring larvae. J Exp Mar Biol Ecol 310: 147-161.

van der Meeren T, Karlsen Ø, Liebig PL, Mangor-Jensen A. 2014. Copepod production in a saltwater pond system: a reliable method for achievement of natural prey in start-feeding of marine fish larvae. Aquac Eng 62: 17-27. 
van der Meeren T, Olsen RE, Hamre K, Fyhn HJ. 2008. Biochemical composition of copepods for evaluation of feed quality in production of juvenile marine fish. Aquaculture 274: 375-397.

Wagemans F, Focant B, Vandewalle P. 1998. Early development of the cephalic skeleton in the turbot. J Fish Biol 52: 166-204.
Wilcox JA, Tracy PL, Marcus NH. 2006. Improving live feeds effect of a mixed diet of copepod nauplii (Acartia tonsa) and rotifers on the survival and growth of first-feeding larvae of the southern flounder, Paralichthys lethostigma. J World Aquac Soc 37: 113-120.

Cite this article as: Bruno E, Mahjoub M-S, Hansen BW, Munk P, Støttrup JG. 2017. Feeding behavior and capture success of turbot Psetta maxima larvae during the transition from upright to tilted swimming position. Aquat. Living Resour. 30 : 35 